\title{
Emissive lead(II) benzenedicarboxylate metal-organic frameworks
}

\author{
ABDUL MALIK P PEEDIKAKKAL ${ }^{\mathrm{a}, *}$ (i) and MOHAMMAD QAMAR ${ }^{\mathrm{b}}$ \\ ${ }^{a}$ Department of Chemistry, King Fahd University of Petroleum and Minerals, Dhahran 31261, Saudi Arabia \\ ${ }^{\mathrm{b}}$ Centre of Excellence in Nanotechnology (CENT), King Fahd University of Petroleum and Minerals, Dhahran \\ 31261, Saudi Arabia \\ E-mail: abdulmalik@kfupm.edu.sa
}

MS received 30 October 2017; revised 7 February 2018; accepted 19 February 2018; published online 16 April 2018

\begin{abstract}
Two known $\mathrm{Pb}(\mathrm{II})$ metal-organic frameworks (MOFs), pseudo-supramolecular isomeric pairs synthesized namely, $\left[\mathrm{Pb}_{3}(\mathrm{BDC})_{3}(\mathrm{DMF})_{3.5}\right](\mathbf{1})$ and $\left[\mathrm{Pb}(\mathrm{BDC})\left(\mathrm{H}_{2} \mathrm{O}\right)\right](\mathbf{2})$ (where $\mathrm{BDC}=$ benzenedicarboxylate) were synthesized and reexamined their structures to determine the topology of the networks. In that $\mathbf{1}$ displayed a 3D (10,3)- $b$ linked network with having the ths topology whereas 2 shows a $(6,3) 2 \mathrm{D}$ layers interconnected to a 3D framework structure. Remarkably, the desolvation of both $\mathbf{1}$ and $\mathbf{2}$ cause structural transformation to a known $3 \mathrm{D}$ network structure of $[\mathrm{Pb}(\mathrm{BDC})]_{n}(\mathbf{3})$ as established by $\mathrm{X}$-ray powder diffraction patterns. Photoluminescence studies in the solid-state at room temperature of 1-3 compounds exhibit interesting luminescence close to white light region due to ligand-to-metal charge-transfer (LMCT).
\end{abstract}

Keywords. Metal-organic frameworks (MOFs); lead (II); structural transformation; photoluminescence; white light emission.

\section{Introduction}

White-light emitting (WLE) materials have generated substantial attention in recent years owing to their application in lightings and displays. ${ }^{1}$ Conventionally, white light is created via exciting multiphosphors using UV LED ${ }^{2}$ mixing blue LED with yellow phosphor, ${ }^{3}$ and blending multi-LED. However, this method may cause problems due to color aging. ${ }^{4}$ Such problems can be solved by developing direct WLE from single-component materials. WLE of single-component material is unusual but identified in polymers, ${ }^{5}$ organic molecules, ${ }^{6}$ ceramics, ${ }^{7}$ hybrid inorganic materials, ${ }^{8}$ and nanomaterials. ${ }^{9}$ Luminescent Metal-organic frameworks (L-MOFs) have been established as emissive solid-state materials which could deliver boundless prospects for constructing single-component WLE. ${ }^{10}$ The luminescence can be generated from both organic ligands and metal centers through ligand-metal/metalligand charge transfer (LMCT/MLCT). ${ }^{11,12}$ Presently, majority of the investigations are concentrated on lanthanides $\mathrm{L}-M O F s^{13}$ or d-block transition metal L-MOFs. ${ }^{14}$

Despite its toxicity, lead(II) compounds have shown promising applications in organic light-emitting diodes, electroluminescence, fluorescent sensors, and photovoltaic conversion. ${ }^{15}$ Lead(II) has the capability to express interesting and rare topologies of various framework and structures owing to its flexible coordination geometries ( 2 to 10 ) with huge ionic radius $(1.20 \AA) .{ }^{16}$ The outer electronic configuration with $6 \mathrm{~s}^{2}$ lone pair has stimulated enormous attention in photophysics, photochemistry and coordination chemistry due to their exceptional coordination priority and electronic intrinsic properties. ${ }^{17}$ Lead(II) MOFs have also shown interesting photophysical properties like luminescence ${ }^{17,18}$ and birefringence. ${ }^{19}$

In this report, we studied two known pseudo-supramolecular isomeric MOFs $\left[\mathrm{Pb}_{3}(\mathrm{BDC})_{3}(\mathrm{DMF})_{3.5}\right]^{16 \mathrm{a}}(\mathbf{1})$ and $\left[\mathrm{Pb}(\mathrm{BDC})\left(\mathrm{H}_{2} \mathrm{O}\right)\right]^{20}(\mathbf{2})$. Both compounds have been synthesized via modified procedure from the reported methods. Compound $\mathbf{1}$ was synthesized from the reac-

\footnotetext{
*For correspondence

Electronic supplementary material: The online version of this article (https://doi.org/10.1007/s12039-018-1441-4) contains supplementary material, which is available to authorized users.
} 
tion of $\mathrm{H}_{2} \mathrm{BDC}$ with $\mathrm{Pb}\left(\mathrm{NO}_{3}\right)_{2}$ in $\mathrm{DMF}$ (DMF = dimethylformamide), while the reaction of $\mathrm{H}_{2} \mathrm{BDC}$ with $\mathrm{Pb}\left(\mathrm{NO}_{3}\right)_{2}$ in $\mathrm{DMF} / \mathrm{H}_{2} \mathrm{O}$ afforded 2. The topological structures of both compounds were studied. 1 forms four $\mathrm{Pb}$ (II) hexa-coordinated geometry linked by linear trinuclear cluster and that results in a 3D non-interpenetrated net with (10,3)- $b$ linked with having the ths topology. However, 2 exhibits hexa-nuclear rings and these rings form a $(6,3)$ connected layers. These layers are linked further through bridging BDC ligands that make 3D non-interpenetrated MOF net with a novel topology. Interestingly, compounds $\mathbf{1}$ and $\mathbf{2}$ undergo 3D $\rightarrow$ 3D structural transformation via desolvation to the desolvated form known in the literature, ${ }^{21}[\mathrm{~Pb}(\mathrm{BDC})]_{n}(\mathbf{3})$ was confirmed by $\mathrm{X}$-ray powder diffraction analysis. Photoluminescence studies in the solid-state at room temperature exhibit very interesting emission close to the white light region, probably due to the chargetransfer from ligand-to-metal (LMCT).

\section{Experimental}

\subsection{Methods and materials}

All the chemicals were purchased from commercial sources and used as received. All solvents used were of reagent grade. The yields of 1-2 are reported with respect to the metal salts. The ${ }^{1} \mathrm{H}$ NMR spectra were recorded in a Bruker ACF $300 \mathrm{FT}-$ NMR spectrometer with TMS as an internal reference. FT-IR spectra were recorded from KBr pellets (FTS 165 Bio-Rad FT-IR). Thermogravimetric analysis for metal complexes was run on a TA Instrument SDT 2960 TGA Thermal Analyzer. Samples were heated at a constant rate of $5{ }^{\circ} \mathrm{C} \mathrm{min}^{-1}$ from room temperature to $600^{\circ} \mathrm{C}$ and the samples held in a continuous flow nitrogen atmosphere. Photoluminescence spectra of the solid samples were recorded on a Horiba Flourolog-3 spectrometer. All the spectra were recorded with $2 \mathrm{~nm}$ spectral slit width.

\subsection{Synthesis}

2.2a Synthesis of $\left[\mathrm{Pb}_{3}(B D C)_{3}(D M F)_{3.5}\right](\mathbf{1}): \quad \mathrm{A}$ mixture of $\mathrm{Pb}\left(\mathrm{NO}_{3}\right)_{2}(0.05 \mathrm{mmol}, 0.017 \mathrm{~g})$ and $\mathrm{H}_{2} \mathrm{BDC}(0.05$ mmol, $0.008 \mathrm{~g}$ ) in $1.5 \mathrm{~mL}$ DMF was heated in a sealed vial at $115^{\circ} \mathrm{C}$. Colorless rod-like crystals were formed after two days, decanted and air dried. [Yield: $19.1 \mathrm{mg}, 84 \%$ ] Elemental analysis: Calculated for $\mathrm{Pb}_{3} \mathrm{C}_{34.5} \mathrm{~N}_{3.5} \mathrm{O}_{15.5} \mathrm{H}_{36.5}$ (1369.69): C, 30.0; H, 2.7; N, 3.6\%. Found: C, 29.59; H, 2.34; N, $3.2 \%$. IR $v / \mathrm{cm}^{-1}: 1645 \mathrm{~s}, 1546 \mathrm{~s}, 1374 \mathrm{~s}, 1103 \mathrm{~m}, 832 \mathrm{~m}$, $746 \mathrm{~m}, 521 \mathrm{~m}$. Thermal gravimetric analysis (DMF weight loss $\%$ ) Calculated $18.6 \%$ Found $17.7 \%$.

2.2b Synthesis of $\left[\mathrm{Pb}(\mathrm{BDC})\left(\mathrm{H}_{2} \mathrm{O}\right)\right](2)$ : A mixture of $\mathrm{Pb}\left(\mathrm{NO}_{3}\right)_{2}(0.05 \mathrm{mmol}, 0.017 \mathrm{~g})$ and $\mathrm{H}_{2} \mathrm{BDC}(0.05 \mathrm{mmol}$,
$0.008 \mathrm{~g})$ in $2 \mathrm{~mL} \mathrm{DMF} / \mathrm{H}_{2} \mathrm{O}$ (3:1) was heated in a sealed vial at $85{ }^{\circ} \mathrm{C}$. Colorless block-like crystals were formed after two days, decanted and air dried. [Yield: $14.5 \mathrm{mg}, 75 \%$ ] Elemental analysis: Calculated for $\mathrm{PbC}_{8} \mathrm{O}_{5} \mathrm{H}_{6}$ (389.33): C, 24.68; H, 1.55\%. Found: C, 24.91; H, 1.59\%. IR v $/ \mathrm{cm}^{-1}$ : $1636 \mathrm{w}, 1528 \mathrm{~s}, 1358 \mathrm{~s}, 1012 \mathrm{~m}, 816 \mathrm{~m}, 746 \mathrm{~m}, 517 \mathrm{~m}$. Thermal gravimetric analysis $\left(\mathrm{H}_{2} \mathrm{O}\right.$ weight loss \%) Calculated $4.6 \%$; Found $4.2 \%$.

\section{Results and Discussion}

\subsection{Synthesis}

$\mathrm{Pb}$ (II) MOFs 1-2 have been synthesized using the modified procedure reported previously. ${ }^{16 a, 20}$ Both compounds were isolated from the solvothermal method in different reaction conditions. The difference in the temperature and water addition in the solvothermal conditions generated $\mathbf{1}$ and $\mathbf{2}$ with two different connectivities between $\mathrm{Pb}(\mathrm{II})$ and $\mathrm{BDC}$ ligands in the threedimensional structure. Apart from these two forms, a third form without any solvent, $[\mathrm{Pb}(\mathrm{BDC})]_{n}(3)$ had been reported in 2009. ${ }^{21}$ The influence of water on the crystallization conditions certainly altered the final topology of the structures. ${ }^{22}$

\subsection{Crystal structures of compounds $1 \& 2$}

Although Batten and co-workers reported the crystal structure of $\mathbf{1}$ in 2007, the detailed crystal description was not given. ${ }^{16 a}$ The single crystal X-ray diffraction studies reveal that $\mathbf{1}$ crystallizes in monoclinic system with $C 2 / c$ space group. The asymmetric units contain one unit of $\left[\mathrm{Pb}_{3}(\mathrm{BDC})_{3}(\mathrm{DMF})_{3.5}\right]$. There are three crystallographically independent $\mathrm{Pb}$ (II) atoms (Figure 1). All the $\mathrm{Pb}$ (II) centers display highly-distorted hemidirected six-coordinate geometry. The distorted $\mathrm{Pb}(\mathrm{II})$ environment is caused by the stereochemically active lone pair. Of the six pairs of carboxylate oxygen atoms in the asymmetric unit, two pairs $(\mathrm{O} 1 \& \mathrm{O} 2 ; \mathrm{O} 11$ \& $\mathrm{O} 12$ ) are exclusively chelating and the $\mathrm{O} 4, \mathrm{O} 5, \mathrm{O} 8$ and O9 oxygen atoms in the rest of the carboxylate ligands are involved in both chelation and bridging $\left(\mu_{2}-\eta^{1}\right.$ : $\eta^{1,2}$ ) mode. $\mathrm{Pb} 1$ has seven-coordinate geometry with two chelating carboxylates, two DMF molecules and a bridging oxygen atom, $\mathrm{O} 8$. The $\mathrm{O} 4$ atom also bridges the nearby $\mathrm{Pb} 3$ atom. $\mathrm{Pb} 3$ has six-coordinate geometry with two chelating carboxylates, one DMF molecule and a bridging oxygen atom. The $\mathrm{Pb} \cdots \mathrm{Pb}$ are separated by $4.366 \AA$. The two six-coordinate $\mathrm{Pb} 3$ atoms are bridged by an $\mathrm{O} 9$ oxygen atom, in addition to two chelating carboxylate oxygen atoms and one DMF molecule 


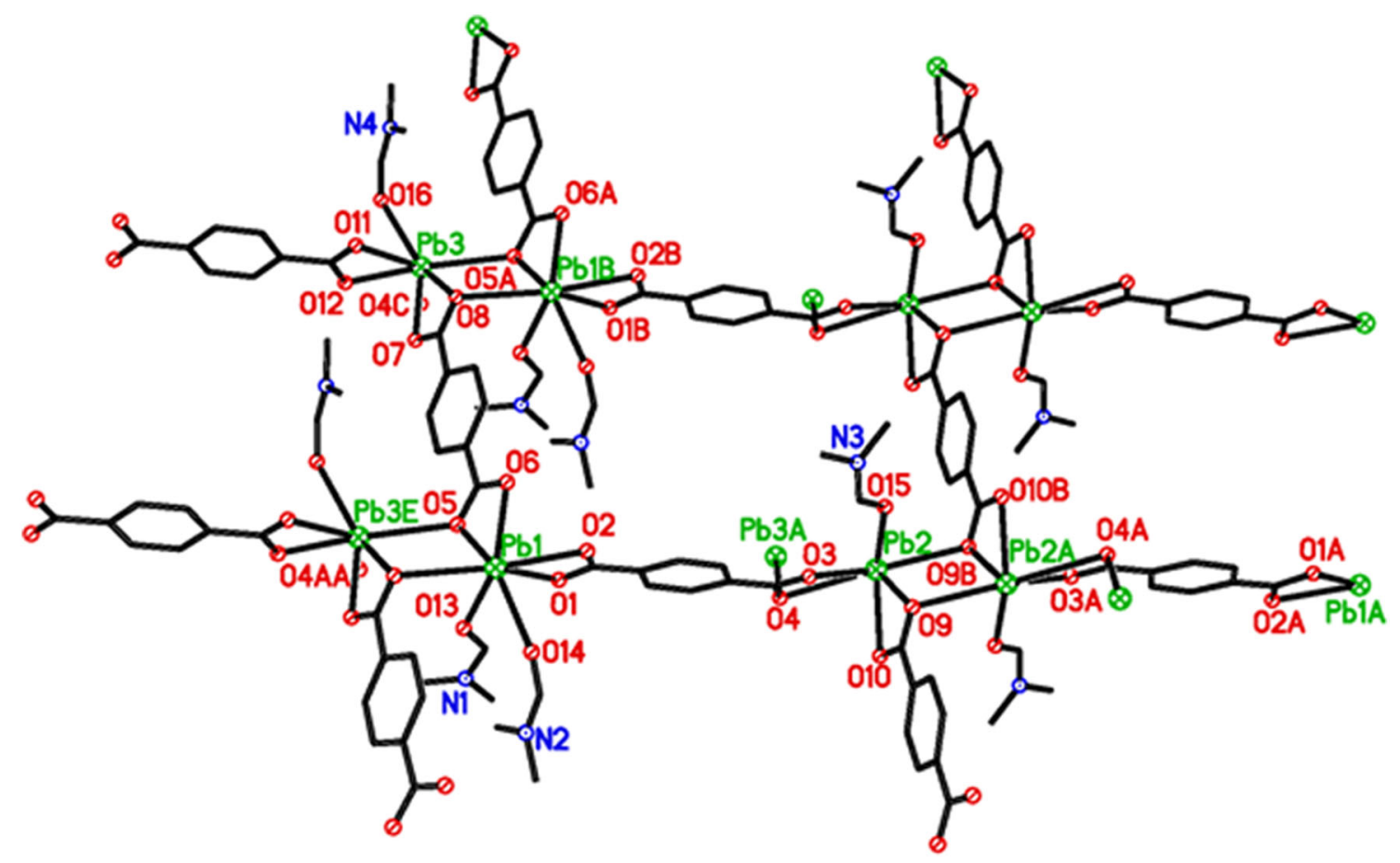

Figure 1. Coordination environment around $\mathrm{Pb}(\mathrm{II})$ atoms and connectivity of $\mathbf{1}$.

around them. This connectivity generates roughly a twodimensional sheet structure. These sheets are further mended through $\mathrm{Pb} 2-\mathrm{O} 4-\mathrm{Pb} 3$ bonds to produce threedimensional architecture. The overall structure is made up of (10,3)- $b$ network with ths topology as shown in Figure 2. The topology analysis of the network was conducted using TOPOS ${ }^{23}$ by considering the $\mathrm{Pb} 1$ and carbon atom of the carboxylate anions as the point of extension or nodes in the structure. The connectivity of these nodes forms shortest circuits comprising of ten nodes, where each node is inter-connected to three other nodal units. Several porous MOFs have been reported with $(10,3)$ network topologies. ${ }^{24,25}$ The most symmetrical of these is the cubic $(10,3)-a$ net or srs net. ${ }^{22 b}$ Other $(10,3)$ nets include $(10,3)-b$ (ths), (10,3)- $c$ (bto), (10,3)$d$ (utp) nets. The most common (10,3)- $a$ and (10,3)- $b$ and others are less common. Compound 1 has $(10,3)-b$ connected net with ths topology. This net is characterized by crosslinked zig-zag chains formed from the $\mathrm{Pb}$ (II) centers which acts as the 3-connected nodes. Large cavities were found to be present in $\mathbf{1}$ after removal of occluded and coordinated solvent. The total effective void volume occupied by coordinated DMF molecules is $42.2 \%$ per unit cell as calculated using PLATON. ${ }^{26}$

Compound $\mathbf{2}$ crystallizes in monoclinic space group $P 2_{1} / c$ as reported earlier. ${ }^{20}$ There is a slight change in the crystallographic parameters especially along $c$-axis, probably due to coordinated water, from the reported dehydrated form, $[\mathrm{Pb}(\mathrm{BDC})]_{n}$ which crystallized in (a)

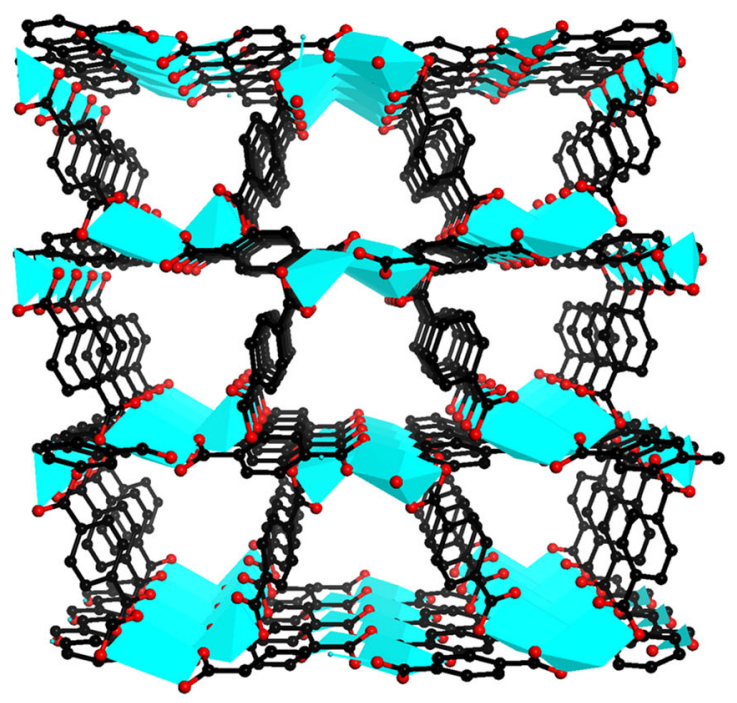

(b)

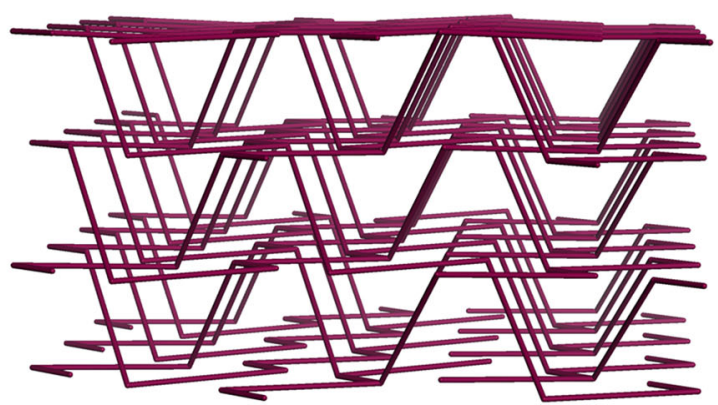

Figure 2. (a) Perspective view of the 3D structure of 1. (b) Perspective view of the $(10,3)$ network topology in $\mathbf{1}$. 
(a)

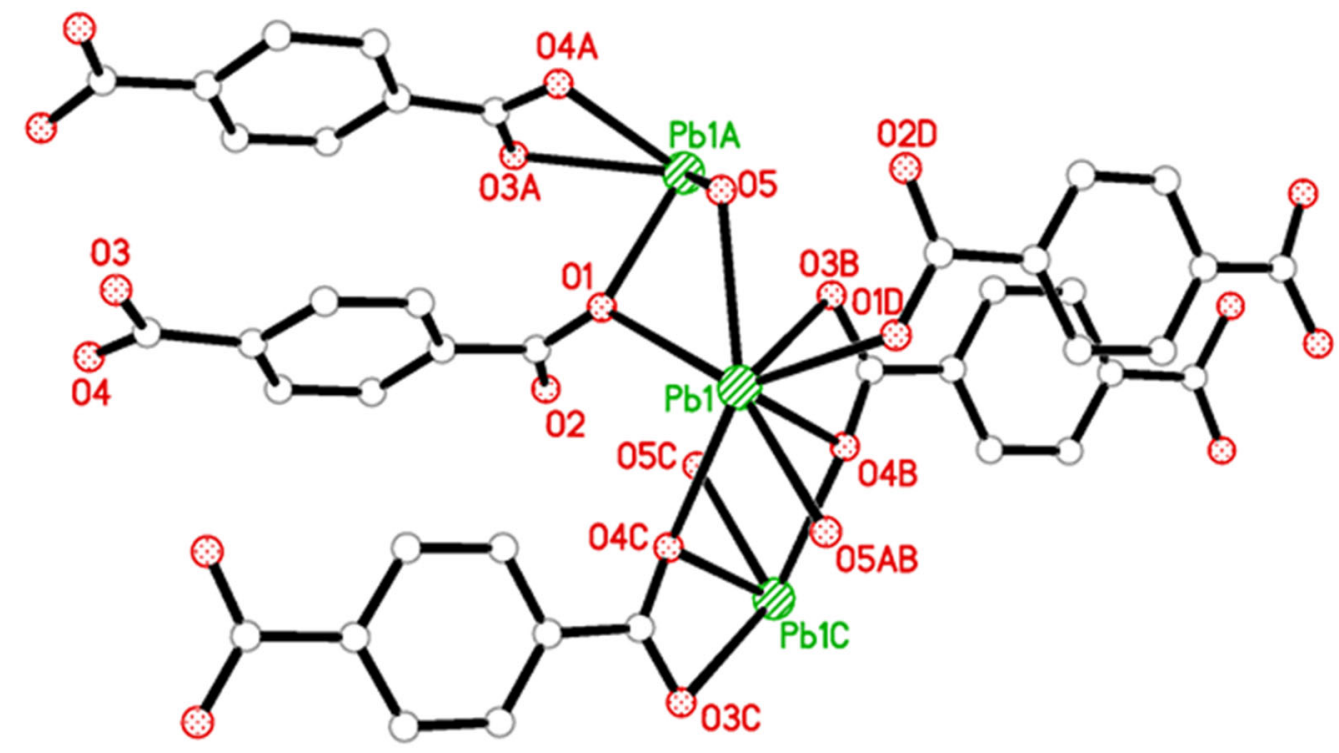

(b)

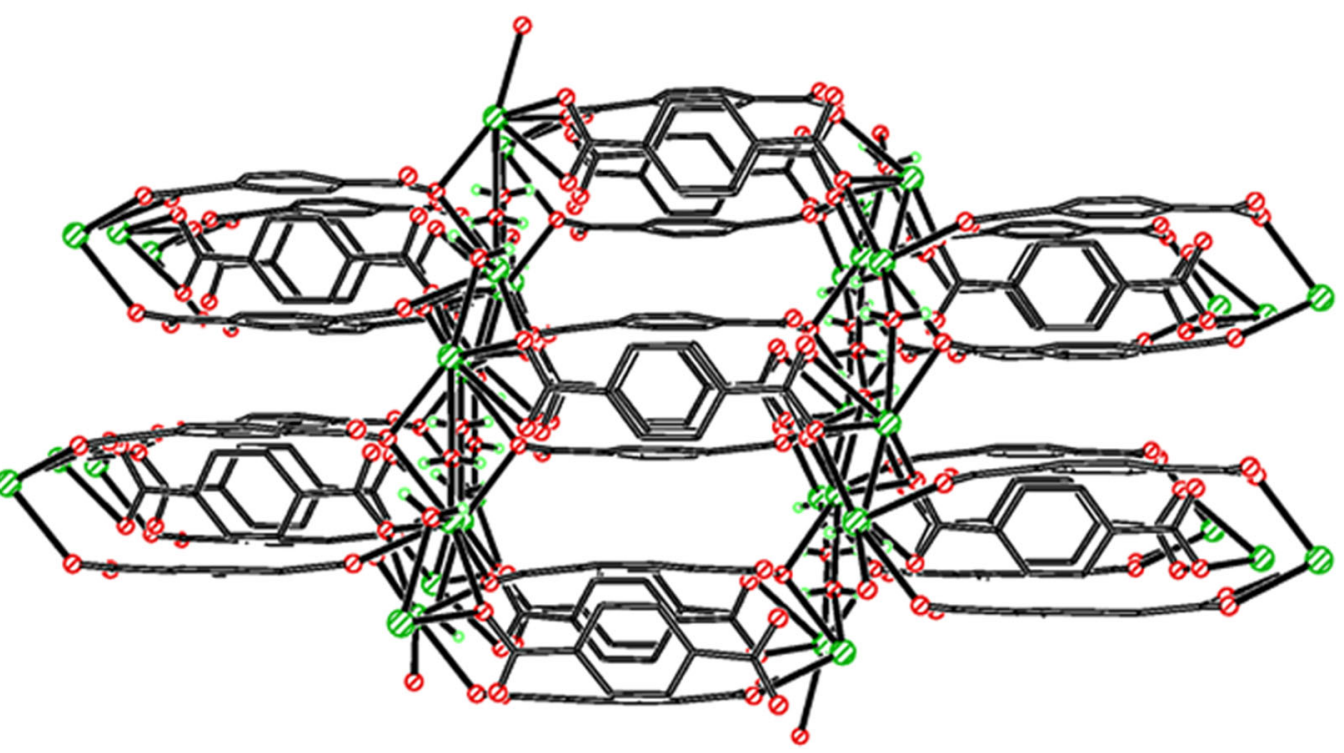

Figure 3. (a) Connectivity and coordination environment at $\mathrm{Pb}(\mathrm{II})$ in 2. (b) A portion of the threedimensional structure in 2.

orthorhombic space group $\mathrm{Pbca} .^{21}$ The asymmetric unit in 2 contains one formula unit of $\left[\mathrm{Pb}(\mathrm{BDC})\left(\mathrm{H}_{2} \mathrm{O}\right)\right]$. The coordination environment of $\mathrm{Pb} 1$ as shown in the Figure 3a has highly-distorted hemi-directed sevencoordinate geometry. $\mathrm{Pb} 1$ is coordinated to five oxygen atoms from BDC ligands and two oxygen atoms from the coordinated water molecules. Of the two carboxylate groups, one with $\mathrm{O} 4$ and $\mathrm{O} 5$ atoms has $\mu_{2}-\eta^{1}: \eta^{1,2}$ bonding mode while in the second carboxylate group. $\mathrm{O} 2$ was bridging two $\mathrm{Pb}(\mathrm{II})$. The coordination geometry at $\mathrm{Pb}$ (II) can be described as highly distorted capped pentagonal pyramid with stereochemically active lone pair probably opposite to $\mathrm{O} 4$ atom. Very interestingly, a pair of adjacent BDC ligands oriented in parallel is bridging two $\mathrm{Pb}$ (II) as shown in Figure 3b. The BDC ligand is planar (best plane rms, $0.0867 \AA$ ). The strain is relieved by slighting slip stacked such that the $\mathrm{C} 6$ atom is closer to the centroid of the other BDC ring by $3.327 \AA$. The aqua ligand is bridging the adjacent $\mathrm{Pb}(\mathrm{II})$ atoms forming a zigzag $\mathrm{PbO}$ chain roughly along $b$-axis. The adjacent chains are cross-linked to each other and form a 2D layer like with $(6,3)$ topology (Figure 4a). Infinite $(6,3)$ sheets are further connected by BDC ligands to form 3D non-interpenetrated framework as shown in Figure 4 b. Calculation using PLATON ${ }^{26}$ shows that there is no effective void volume in $\mathbf{2}$ unlike in $\mathbf{1}$. 
(a)

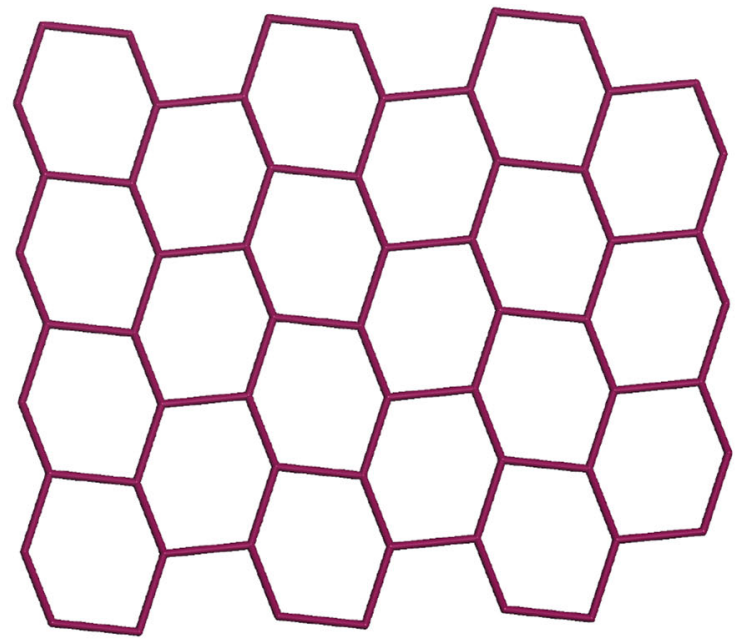

(b)

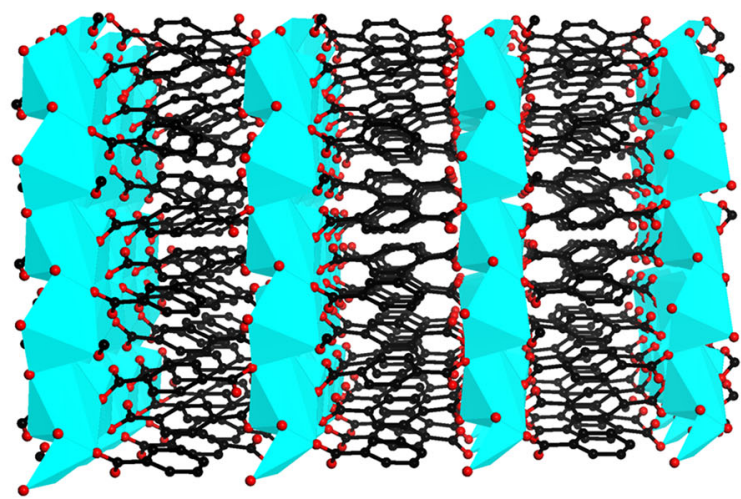

Figure 4. (a) $\mathrm{A}$ fragment of $\mathrm{Pb}$ (II) hexanuclear rings in 2 which subsequently form the honeycomb $2 \mathrm{D}(6,3)$ connected topology. (b) Perspective view of the packing structure of compound 2.

\subsection{Structural transformation via desolvation}

The single crystal structure of the $[\mathrm{Pb}(\mathrm{BDC})]_{n}(3)$ also has been reported in the literature. ${ }^{21}$ Hence, it prompted us to investigate the desolvation of $\mathbf{1}$ and $\mathbf{2}$ to find out whether they are converted to form $\mathbf{3}$. The thermogravimetric studies show that all the coordinated DMF molecules were lost from $\mathbf{1}$, in the temperature zone $150-250{ }^{\circ} \mathrm{C}$ (Weight loss observed, $17.7 \%$ and calculated, $18.7 \%$ ) while the aqua ligand was lost in the temperature region $115-150{ }^{\circ} \mathrm{C}$ (Weight loss observed, $4.2 \%$ and calculated, $4.6 \%$ ) for 2 (Figure S8 in Supplementary Information). Since both solids were thermally stable after the solvent loss until $\mathrm{ca}$ $380{ }^{\circ} \mathrm{C}$, the PXRD patterns were recorded after heating both the solids at $350{ }^{\circ} \mathrm{C}$ for $2 \mathrm{~h}$. A comparison of the PXRD patterns of these desolvated solids with the simulated PXRD patterns of the known compound revealed that desolvated $\mathbf{1}$ has probably transformed to $\mathbf{3}$ whereas dehydrated $\mathbf{2}$ is completed converted to $\mathbf{3}$ (Figure S6 and S7 in Supplementary Information). This is not a single-crystal-to-single-crystal conversion and has been termed as crystal-to-crystal transformation. Crystal-to-crystal transformation in the solid-state has been observed before. ${ }^{27}$

\subsection{Photoluminescence studies}

Due to their potential applications in photochemistry, chemical sensors, and electroluminescent displays, LMOFs are quite attractive for the development of WLE materials. For this reason, the solid-state photoluminescence property of $\mathbf{1}$ and $\mathbf{2}$ was investigated. Solid-state luminescence emission under UV light for 1-3 are shown in Figure 5. It is known that metal-free BDC ligand showed emission at $375 \mathrm{~nm}$, which can be attributed to $\pi \rightarrow \pi *$ transition. ${ }^{28}$ Contrarily, compound 1 exhibits emission maximum at $512 \mathrm{~nm}$ upon excitation at 332 $\mathrm{nm}$ as shown in Figure 6. The emission peak of $\mathbf{1}$ is red-shifted by about $130 \mathrm{~nm}$ compared to that of ligand probably due to the coordination of the ligand with $\mathrm{Pb}$ (II). Compound $\mathbf{2}$ exhibits emission maximum located at $526 \mathrm{~nm}$ upon excitation at $329 \mathrm{~nm}$ as shown in Figure 6. The emission peak of $\mathbf{2}$ is red-shifted by about $150 \mathrm{~nm}$ compared to that of the ligand. Compound

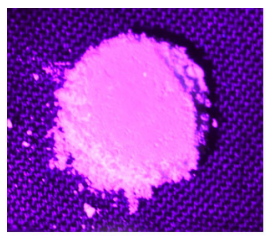

(a)

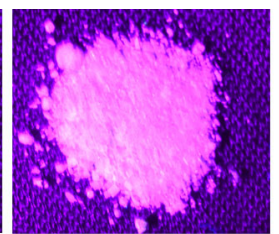

(b)

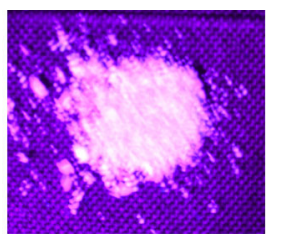

(c)
Figure 5. Photographs show the emission of powder samples of (a) 1 (b) 2 and (c) 3, under UV light.

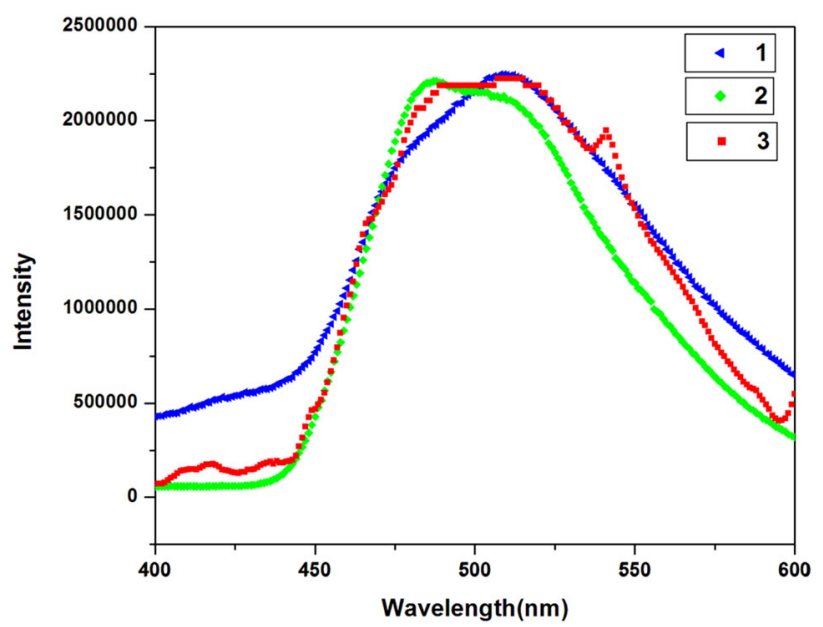

Figure 6. Solid-state luminescent emission spectra of compound 1-3 $\left(\lambda_{\mathrm{ex}}=332 \mathrm{~nm}, \lambda_{\mathrm{ex}}=329 \mathrm{~nm}\right.$ and $\lambda_{\mathrm{ex}}=320 \mathrm{~nm}$ for $\mathbf{1}, \mathbf{2}$ and $\mathbf{3}$, respectively) at room temperature. 


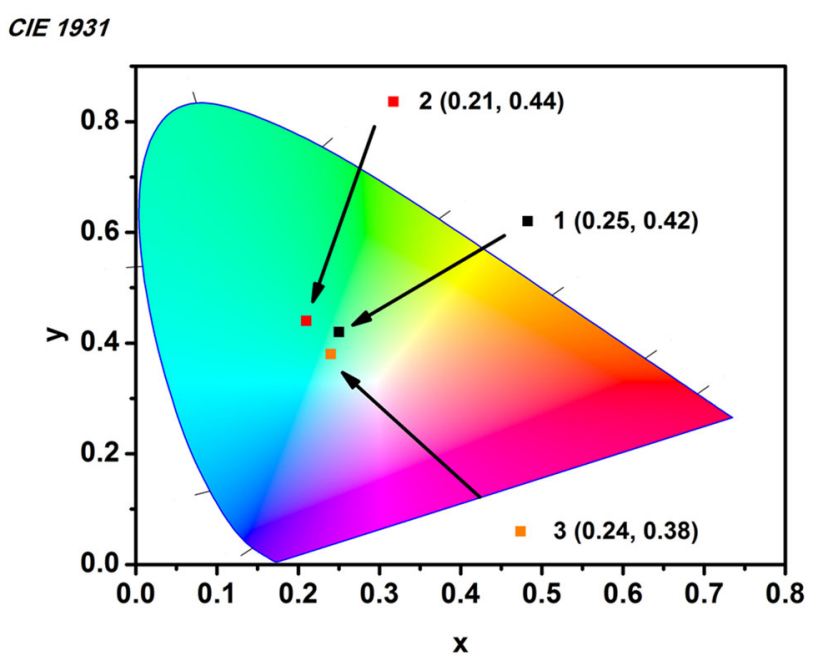

Figure 7. The CIE chromaticity diagram for 1-3 $\left(\lambda_{\mathrm{ex}}=332 \mathrm{~nm}, \lambda_{\mathrm{ex}}=329 \mathrm{~nm}\right.$ and $\lambda_{\mathrm{ex}}=320 \mathrm{~nm}$ for $\mathbf{1 , 2}$ and $\mathbf{3}$, respectively).

3 exhibits emission maximum located at $511 \mathrm{~nm}$ upon excitation at $320 \mathrm{~nm}$ as shown in Figure 6. The emission peak of $\mathbf{3}$ is red-shifted by about $136 \mathrm{~nm}$ compared to that of the ligand. The difference in the PL obtained for $\mathbf{3}$ compared to 1-2 is attributed to the removal of solvent molecules. Particularly, the peak obtained at around $545 \mathrm{~nm}$ in $\mathbf{3}$ is probably due to vibrational structure. The emissions of the compounds 1-3 are attributed to the ligand-to-metal charge transfer (LMCT) between the delocalized $\pi$-bond of carboxylate groups and $p$ orbitals of $\mathrm{Pb}(\mathrm{II})$ centers. ${ }^{29}$ The color of the emission has been quantified with the Commission Internationale de l'Eclairage (CIE) chromaticity diagram in Figure 7. The chromaticity coordinates for $\mathbf{1}$ is $(0.25,0.42)$ when irradiated by $332 \mathrm{~nm}$ light. The coordinates for 2 is $(0.21$, $0.44)$ when irradiated by $329 \mathrm{~nm}$ light and the coordinates for 3 is $(0.24,0.38)$ when irradiated by $329 \mathrm{~nm}$ light. These are located in the gamut, both falling close to the white gamut of the CIE-1931 color space chromaticity diagram. ${ }^{30}$ The compound 3 shows emission which is very close to the white light region as shown in the chromaticity diagram.

\section{Conclusions}

Two pseudo-supramolecular isomers pairs were isolated from $\mathrm{Pb}(\mathrm{II})$ ion and the $\mathrm{BDC}$ ligand by varying the experimental conditions. Compound 1 exhibits a non-interpenetrated 3D network with (10,3)- $b$ linked with having the ths topology. However, compound 2 shows a $(6,3)$ network in which 2D layers are subsequently interconnected through the ligands to form a non-interpenetrated network topology. Interestingly, compound $\mathbf{1}$ and $\mathbf{2}$ undergo $3 \mathrm{D} \rightarrow 3 \mathrm{D}$ structural transformation via desolvation to a solvent-less form, $[\mathrm{Pb}(\mathrm{BDC})]_{n}$ (3) as confirmed by consecutive thermal and X-ray powder pattern analysis. It is important to monitor such structural transformation using powder diffraction patterns in the case of disintegration of single crystal. Solid-state emission of 1-3 was recorded at room temperature. Interestingly, all the compounds display single-component close to white light emission due to ligand-to-metal charge-transfer (LMCT). These studies also open up more opportunities to attain better perception of the fundamental aspects that effect crystal structural transformation and help develop better singlecomponent WLE materials.

\section{Supplementary Information (SI)}

Supplementary information associated with this article including X-ray crystallographic analysis, TGA of 1-2, X-ray powder pattern of 1-3, FT-IR, emission spectra of 1-3, excitation spectra of 1-2 are available at www.ias.ac.in/chemsci.

\section{Acknowledgements}

A. M. P. P. would like to acknowledge the support provided by KACST for funding this work through NSTIP. Project No. 14-ENE2278-04. The author is grateful to Prof. J. J. Vittal (National University of Singapore) for helpful discussion on the article.

\section{References}

1. (a) Waltereit $\mathrm{P}$, Brandt $\mathrm{O}$, Trampert A, Grahn H T, Menniger J, Ramsteiner M, Reiche M and Ploog K H 2000 Nitride semiconductors free of electrostatic fields for efficient white light-emitting diodes Nature $\mathbf{4 0 6}$ 865; (b) Jang E, Jun S, Jang H, Lim J, Kim B and Kim Y 2010 White-light-emitting diodes with quantum dot color converters for display backlights Adv. Mater. 22 3076; (c) Li G, Fleetham T and Li J 2014 Efficient and stable white organic light-emitting diodes employing a single emitter Adv. Mater. 262931

2. Gong X, Wang S, Moses D, Bazan G C and Heeger A J 2005 Multilayer Polymer Light-Emitting Diodes: WhiteLight Emission with High Efficiency Adv. Mater. 172053

3. Fan C and Yang C 2014 Yellow/orange emissive heavymetal complexes as phosphors in monochromatic and white organic light-emitting devices Chem. Soc. Rev. 43 6439

4. Yan B P, Cheung C C C, Kui S C F, Xiang H F, Roy V A L, Xu S J and Che C M 2007 Efficient White Organic Light-Emitting Devices Based on Phosphorescent Platinum(II)/Fluorescent Dual-Emitting Layers Adv. Mater. 193599

5. Wu H B, Zhou G J, Zou J H, Ho C L, Wong W Y, Yang W, Peng J B and Cao Y 2009 Efficient Polymer White-LightEmitting Devices for Solid-State Lighting Adv. Mater. 21 4181 
6. (a) Yang Q Y and Lehn J M 2014 Bright White-Light Emission from a Single Organic Compound in the Solid State Angew. Chem. Int. Edit. 53 4572; (b) Jin X H, Chen C, Ren C X, Cai L X and Zhang J 2014 Bright white-light emission from a novel donor-acceptor organic molecule in the solid state via intermolecular charge transfer Chem. Commun. 5015878

7. Zhang R, Lin H, Yu Y L, Chen D Q, Xu J and Wang Y S 2014 A new-generation color converter for highpower white LED: transparent $\mathrm{Ce}^{3+}$ :YAG phosphor-inglass Laser Photonics Rev. 8158

8. (a) Dohner E R, Hoke E T and Karunadasa H I 2014 Self-Assembly of Broadband White-Light Emitters $J$. Am. Chem. Soc. 136 1718; (b) Dohner E R, Jaffe A, Bradshaw L R and Karunadasa H I 2014 Intrinsic WhiteLight Emission from Layered Hybrid Perovskites J. Am. Chem. Soc. 13613154

9. Kim J H, Ko Y H, Cho J H, Gong S H, Ko S M and Cho Y H 2014 Toward highly radiative white light emitting nanostructures: a new approach to dislocationeliminated GaN/InGaN core-shell nanostructures with a negligible polarization field Nanoscale 2614213

10. (a) Heine J and Muller-Buschbaum K 2013 Engineering metal-based luminescence in coordination polymers and metal-organic frameworks Chem. Soc. Rev. 42 9232; (b) Allendorf M D, Bauer C A, Bhakta R K and Houk R J T 2009 Luminescent metal-organic frameworks Chem. Soc. Rev. 38 1330; (c) Haider G, Usman M, Chen T-P, Perumal P, Lu K-L, Chen Y-F 2016 Electrically Driven White Light Emission from Intrinsic Metal-Organic Framework ACS Nano 10 8366; (d) Wu Z-F, Tan B, Deng Z-H, Xie Z-L, Fu J-J, Shen N-N, Huang X-Y 2016 Dual-Emission Luminescence of Magnesium Coordination Polymers Based on Mixed Organic Ligands Chem. Eur. J. 221334

11. (a) Chen J, Zhang Q, Zheng F K, Liu Z F, Wang S $\mathrm{H}$, Wu A Q and Guo G C 2015 Intense photo- and tribo-luminescence of three tetrahedral manganese(II) dihalides with chelating bidentate phosphine oxide ligand Dalton Trans. 44 3289; (b) Han Y H, Tian C B, Li Q H, Du S W 2014 Highly chemical and thermally stable luminescent $\mathrm{Eu}_{x} \mathrm{~Tb}_{1-x}$ MOF materials for broad-range $\mathrm{pH}$ and temperature sensors J. Mater. Chem. C 28065

12. Wei Z, Gu Z Y, Arvapally R K, Chen Y P, McDougald R N, Ivy J F, Yakovenko A A, Feng D M, Omary A and Zhou H C 2014 Rigidifying Fluorescent Linkers by Metal-Organic Framework Formation for Fluorescence Blue Shift and Quantum Yield Enhancement J. Am. Chem. Soc. 1368269

13. (a) Gao X, Chang S, Liu H and Liu Z 2016 A Promising White-Light-Emitting Material Constructed from Encapsulating Eu3+/Tb3+ Hybrid Ions into a Robust Microporous Metal-Organic Framework Eur. J. Inorg. Chem. 2837; (b) Li Y-F, Wang D, Liao Z, Kang Y, Ding W-H, Zheng X-J, Jin L-P 2016 Luminescence tuning of the Dy-Zn metal-organic framework and its application in the detection of Fe(III) ions Mater. J. Chem. C 4 4211; (c) Wang X, Yan P, Li Y, An G, Yao X and Li G 2017 Highly Efficient White-Light Emission and UV-Visible/NIR Luminescence Sensing of Lanthanide Metal-Organic Frameworks Cryst. Growth Des. 17 2178; (d) Xu B, Cheng Y, Hu H-M, Bai C, Wang
X, Yang M-L, Xue G 2016 Syntheses, crystal structures and luminescence properties of lanthanide-based coordination polymers constructed from a functionalized terpyridyl carboxylate ligand CrystEngComm 18 4613; (e) Yang Y, Chen L, Jiang F, Yu M, Wan X, Zhang B and Hong M 2017 A family of doped lanthanide metalorganic frameworks for wide-range temperature sensing and tunable white light emission J. Mater. Chem. C 5 1981; (f) Zhao Y W, Zhang F-Q, Zhang X-M 2016 Single Component Lanthanide Hybrids Based on MetalOrganic Framework for Near-Ultraviolet White Light LED ACS Appl. Mater Interfaces 824123

14. (a) Wang $\mathrm{S} \mathrm{H}$, Zheng F K, Zhang M J, Liu Z F, Chen J, Xiao, Y, Wu A Q, Guo G C and Huang J S 2013 Homochiral zinc(II) coordination compounds based on in-situ-generated chiral amino acid-tetrazole ligands: circular dichroism, excitation light-induced tunable photoluminescence, and energetic performance Inorg. Chem. 52 10096; (b) Wu M F, Liu Z F, Wang S H, Chen J, Xu G, Zheng F K, Guo G C and Huang J S 2011 Structures and photoluminescence of zinc(II) coordination polymers based on in situ generated $1 H$-tetrazolate5-propionic acid ligands CrystEngComm 13 6386; (c) Wu M F, Zheng F K, Wu A Q, Li Y, Wang M S, Zhou W W, Chen F, Guo G C and Huang J S 2010 Hydrothermal syntheses, crystal structures and luminescent properties of zinc(II) coordination polymers constructed by bifunctional tetrazolate-5-carboxylate ligands CrystEngComm 12 260; (d) Xie W, Qin J-S, He W-W, Shao K-Z, Su Z-M, Du D-Y, Li S-L and Lan Y-Q 2017 Encapsulation of an iridium complex in a metal-organic framework to give a composite with efficient white light emission Inorg. Chem. Front. 4 547; (e) Hua C A, Su-Ci M, Kai Z, Cong W C, Wei Z, Jian W A and Jun Q 2017 A New Copper(I) Complex Based on 4-amino-3,5-bis(3-pyridyl)-1,2,4triazole: Synthesis, Crystal Structure, Theoretical Study, Thermal Behavior and Luminescence J. Chem. Sci. 129 185; (f) Ali F, Nayak P K, Periasamy N and Agarwal N 2017 Synthesis, photophysical, electrochemical and electroluminescence studies of red emitting phosphorescent Ir(III) heteroleptic complexes J. Chem. Sci. 129 1391

15. (a) Vogler A and Nikol H 1992 Photochemistry and photophysics of coordination compounds of the main group metals Pure Appl. Chem. 64 1311; (b) Strasser $A$ and Vogler A 2004 Intraligand phosphorescence of lead(II) $\beta$-diketonates under ambient conditions J. Photochem. Photobiol. A165 115; (c) Roy S, Choubey S, Khan K, Mitra P and Ghosh B K Syntheses, molecular and crystalline architectures, and luminescence behaviour of terephthalate bridged heptacoordinated dinuclear lead(II) complexes containing a pentadentate N-donor Schiff base J. Chem. Sci. 125715

16. (a) Yang J, Ma J F, Liu Y Y, Ma J C and Batten S R 2007 Organic-Acid Effect on the Structures of a Series of Lead(II) Complexes Inorg. Chem. 46 6542; (b) Fan S $R$ and Zhu L G 2007 Influence of the Reaction Conditions on the Self-assembly of Lead(II) 5-Sulfosalicylate Coordination Polymers with Chelating Amine Ligands Inorg. Chem. 46 6785; (c) Zhao Y H, Xu H B, Fu Y M, Shao K Z, Yang S Y, Su Z M, Hao X R, Zhu D X and Wang E B 2008 A Series of Lead(II)-Organic Frameworks Based 
on Pyridyl Carboxylate Acid N-Oxide Derivatives: Syntheses, Structures, and Luminescent Properties Cryst. Growth Des. 8 3566; (d) Yang J, Ma J F, Liu Y Y, Ma J C and Batten S R 2009 A Series of Lead(II) Complexes with $\pi-\pi$ Stackings: Structural Diversities by Varying the Ligands Cryst. Growth Des. 9 1894; (e) Yang J, Li G D, Cao J J, Yue Q, Li G H and Chen J S 2007 Structural Variation from 1D to 3D: Effects of Ligands and Solvents on the Construction of Lead(II)-Organic Coordination Polymers Chem. Eur. J. 13 3248; (f) Wardana F Y, Ng S-W and Wibowo A C 2015 The Lead Coordination Polymers Containing Pyrazine-2,3-Dicarboxylic Acid: Rapid Structural Transformations and Cation Exchange Cryst. Growth Des. 155930

17. (a) Deo S H and Godwin A J A 2000 Selective, Ratiometric Fluorescent Sensor for $\mathrm{Pb}^{2+} J$. Am. Chem. Soc. 122 174; (b) Li L, Zhang S, Han L, Sun Z, Luo J and Hong M 2013 A Non-Centrosymmetric Dual-Emissive MetalOrganic Framework with Distinct Nonlinear Optical and Tunable Photoluminescence Properties Cryst. Growth Des. 13 106; (c) Sahu J, Ahmed M and Bharadwaj P K 2013 Structural Diversity and Luminescence Properties of Coordination Polymers Built With a Rigid Linear Dicarboxylate and $\mathrm{Zn}(\mathrm{II}) / \mathrm{Pb}(\mathrm{II})$ Ion Cryst. Growth Des. 13 2618; (d) Huang K-L, Liu X, Li J-K, Ding Y-W, Chen X, Zhang M-X, Xu X-B and Song X-J 2010 ThreeDimensional Metal(II)-Organic Coordination Polymers from Binuclear, Trinuclear, and Polynuclear Clusters Bridged by $p$-Benzenediacrylates: Syntheses, Topologies, Photosensitive Properties, and Hydrogen Uptake Cryst. Growth Des. 101508

18. (a) Zhao Y-H, Xu H-B, Fu Y-M, Shao K-Z, Yang SY, Su Z-M, Hao X-R, Zhu D-X and Wang E-B 2008 A Series of Lead(II)-Organic Frameworks Based on Pyridyl Carboxylate Acid N-Oxide Derivatives: Syntheses, Structures, and Luminescent Properties Cryst. Growth Des. 8 3566; (b) Zhao Y-H, Xu H-B, Shao K-Z, Xing Y, Su Z-M and Ma J-F 2007 Syntheses, Characterization, and Luminescent Properties of Three 3D Lead-Organic Frameworks with 1D Channels Cryst. Growth Des. 7 513; (c) Li L, Zhang S, Han L, Sun Z, Luo J and Hong M A 2013 Non-Centrosymmetric Dual-Emissive Metal-Organic Framework with Distinct Nonlinear Optical and Tunable Photoluminescence Properties Cryst. Growth Des. 13106

19. (a) Katz M J, Kaluarachi H, Batchelor R J, Bokov A A, Ye Z-G and Leznoff D B 2007 Highly birefringent materials designed using coordination polymer synthetic methodology Angew. Chem. Int. Edit. 46 8804; (b) Katz M J, Aguiar P M, Batchelor R J, Bokov A A, Ye Z-G, Kroeker S and Leznoff D B 2006 Structure and Multinuclear Solid-State NMR of a Highly Birefringent Lead-Gold Cyanide Coordination Polymer J. Am. Chem. Soc. 128 3669

20. Dale S H, Elsegood M R J and Kainth S 2004 Poly[lead(II)- $\mu_{2}$-aqua- $\mu_{4}$-terephthalato] Acta Cryst. C60 m76

21. Zhang P L, Yong H X, Chun G W, Jing L, Xiao Q Z, Mao F G and Shu Y N 2009 ANew Coordination Poly- mer $[\mathrm{Pb}(1,4-\mathrm{BDC})]_{n}$ Containing a Unique $\mu_{6}$-Bridging Coordination Mode Z. Anorg. Allg. Chem. 1650

22. (a) Moulton B and Zaworotko M J 2001 From Molecules to Crystal Engineering: Supramolecular Isomerism and Polymorphism in Network Solids Chem. Rev. 101 1629; (b) Batten S R 2001 Topology of interpenetration CrystEngComm 3 67; (c) Biradha K, Sarkar M and Rajput L 2006 Crystal engineering of coordination polymers using 4, 4/-bipyridineas a bond between transition metal atoms Chem. Commun. 4169; (d) Nangia A 2010 Supramolecular chemistry and crystal engineering J. Chem. Sci. 122 295

23. Blatov V A 2006 Multipurpose crystallochemical analysis with the program package TOPOS IUCr CompComm Newsletter 74

24. Batten S R and Robson R 1998 Interpenetrating Nets: Ordered, Periodic Entanglement Angew. Chem. Int. Edit. 371461

25. (a) Ke Y, Collins D J, Sun D and Zhou H-C 2006 (10,3)-a Noninterpenetrated Network Built from a Piedfort Ligand Pair Inorg. Chem. 45 1897; (b) Kepert C J, Prior T J and Rosseinsky M J A Versatile Family of Interconvertible Microporous Chiral Molecular Frameworks: The First Example of Ligand Control of Network Chirality J. Am. Chem. Soc. 2000 5158; (c) Abrahams B F, Batten S R, Hamit H, Hoskins B F and Robson R A 1996 Wellsian 'three-dimensional' racemate: eight interpenetrating, enantiomorphic (10,3)-a nets, four rightand four left-handed Chem. Commun. 1313; (d) Bradshaw D, Claridge J B, Cussen E J, Prior T J and Rosseinsky M J 2005 Design, Chirality, and Flexibility in Nanoporous Molecule-Based Materials Acc. Chem. Res. 38 273; (e) Ma S, Fillinger J A, Ambrogio M W, Zuo J-L and Zhou H-C 2007 Synthesis and Characterizations of a Magnesium Metal-Organic Framework with the (10,3)-a Net Topology Inorg. Chem. Commun. 10 220

26. Spek A L 2003 PLATON A multipurpose Crystallographic Tool, Ultrecht, The Netherlands

27. (a) Vittal J J 2007 Supramolecular structural transformations involving coordination polymers in the solid-state Coord. Chem. Rev. 251 178; (b) Kuroda R, Higashiguchi $\mathrm{K}$, Hasebe S and Imai Y 2004 Crystal to crystal transformation in the solid state CrystEngComm 6 464

28. Zheng L-Y, Li K, Zhao S, Liu L, Li B-L and Wu B 2016 Syntheses, structures and properties of eight coordination polymers based on bis(imidazole) and biscarboxylate ligands Polyhedron 1041

29. Santra A and Bharadwaj P K 2014 Solvent-Induced Structural Diversity of Partially Fluorinated, Stable $\mathrm{Pb}(\mathrm{II})$ Metal-Organic Frameworks and Their Luminescence Properties Cryst. Growth Des. 14 1476

30. (a) See http://en.wikipedia.org/wiki/CIE_1931_color_ space for more details (accessed on: 20 September, 2017); (b) Silver J and Withnall R 2008 In Luminescent Materials A Kitai (Ed.) (Chicester: John Wiley \& Sons) p. 75 